\title{
A Critical Evaluation of Optimizing the Potential for Ore Recovery from Mine Waste Using Multi-Elemental, Geochemical and Petrographic Analysis (MEGPA)
}

\author{
Tamba Komba \\ Geology Department, Fourah Bay College, University of Sierra Leone, Freetown, Sierra Leone \\ Email: tamba.komba@usl.edu.sl, tamsuccess2015@gmail.com
}

How to cite this paper: Komba, T. (2021) A Critical Evaluation of Optimizing the Potential for Ore Recovery from Mine Waste Using Multi-Elemental, Geochemical and Petrographic Analysis (MEGPA). Journal of Minerals and Materials Characterization and Engineering, 9, 301-315.

https://doi.org/10.4236/jmmce.2021.93021

Received: February 27, 2021

Accepted: May 25, 2021

Published: May 28, 2021

Copyright $\odot 2021$ by author(s) and Scientific Research Publishing Inc. This work is licensed under the Creative Commons Attribution International License (CC BY 4.0).

http://creativecommons.org/licenses/by/4.0/

\begin{abstract}
The growing world demand for metals necessitates the economic extraction of metals from ores of lesser grades and scheduled waste with potential for metal recovery. In which case, efficient skilled-beneficiation is required to achieve such demand. This research paper examines the potential of ore recovery from magmatic Ni-Cu-PGE waste rock in an open pit mine operation. The waste material contains a marginal cut-off grade between the ore and what has been scheduled to be produced as waste throughout its life of mine (LOM). The waste material has the potential for metal recovery to extend the LOM. The main aim was to investigate the appropriateness of the potential for metal recovery using the already generated waste as a baseline model for subsequent waste production. To achieve this aim, the primary objective was to use Multi-elemental, Geochemical and Petrographic Analysis (MEGPA) on carefully selected waste rock samples. While the specific objectives were to examine the liberation of metals and establish optimal cut-off grade based on suitable size fractions for ore recovery. Multi-elemental, geochemical and Petrographic Analysis were carried out on selected size fractions using various instruments such as Scanning Electron Microscope Energy Disperse X-ray (SEM-EDX), X-Ray Diffraction (XRD) and X-Ray Fluorescence (XRF), reflected and transmitted microscopes. Categorization of results shown the predominant bulk mineral abundance to be tremolite, a member of the amphibole group of silicate minerals with composition $\mathrm{Ca}_{2} \mathrm{Si}_{8} \mathrm{O}_{22} \cdot(\mathrm{OH})_{2}$. Moreover, the result revealed that the economic $\mathrm{Ni}$ and $\mathrm{Cu}$ sulphides are hosted in pentlandite and chalcopyrite within the waste samples. Liberation of mineral and recovery of metal are in the finer fractions size below $1.5 \mathrm{~mm}$, and that optimum metal recovery is at $\leq 1 \mathrm{~mm}$. It was concluded from the study that,
\end{abstract}


there is potential for metal recovery from mines waste in finer fractions below $1.5 \mathrm{~mm}$ without posing significant metalliferous acid mine drainage (AMD) risk to the mining environment. It is recommended that further study about the influence on the metallurgical processing of the waste at the selected optimum fractions size, and energy requirement for screening the sample is carried out. Since the PSD (particle size distribution) is critical to both the physical separation processes of the waste and the prediction of metalliferous AMD risk, other methods like advanced UAV 3D photogrammetry and digital image processing method could be used to test for both underestimation and overestimation of PSD. This is important as the amount of mineral liberation, metal recovery and sulphur generation are PSD dependent.

\section{Keywords}

Magmatic, Ni-Cu-PGE, AMD, Size-Fractions, PS, Fragmentation

\section{Introduction}

A wide range of ore and waste particle sizes are produced during various mining activities such as; blasting [1], excavation, grinding and processing etc. An understanding of the distribution and characterization of such particle sizes is pivotal not only to "the life of mine", resource recovery potential and project economics [2] [3] but also requirements for the waste management strategy and mine closure planning. As such, there is an intrinsic link between resource recovery potential metrics and their impacts on the environment. The physical, mineralogical and geochemical properties of "waste" materials stored in waste storage facilities act as potential sources of environmental pollution and degradation [4] [5] through airborne transport of fine particles in drying periods, transportation of fines by surface water during heavy rains, or as dissolved potentially noxious elements in leachates.

It has been hypothesized that different size fractions can greatly influence the amount of metal to be recovered from an orebody, and the risk of metalliferous acid drainage [6] [7]. And the particle size of the as-mined rock influences the economics and thus chosen mining method for excavation, loading, haulage and all downstream activities for both ore processing and waste storage.

According to Siqui et al. and Jug et al. [8] [9], blasting is the primary factor that determines size fractions and their distribution in a mining operation. Drilling and blasting costs may account for up to $25 \%$ - $30 \%$ of the overall operational costs in an open cast mine. Therefore, specification of rock fraction size after blasting is by far one of the most imperative parameters in product optimization of metal recovery in the mineral industry.

Mining and ore-processing activities generate large quantities of sulphide-bearing mine waste rock and tailings globally. In general, small portions of metals occur- 
ring in mined ores are not recovered by milling and processing operations and consequently are left in tailings [6] [10]. These are potential sources of acid mine drainage

The amount of mine waste that is generated and metal recovery potential from mine waste in any mining operation are controlled by several factors. These factors are closely intertwined, and could greatly influence the different stages and processes in a mine. A well-developed resource and grade control model, good pit design, the experience of digging operators can have an immeasurable impact on size fractions, and ultimately on the amount and type of waste produced and ore recovery potential.

Among many of the emerging techniques in metal recovery from mine waste, the influence of size fractions has not been well explored in optimizing the potential for metal recovery An understanding of mineral distribution in various size fractions is pivotal in achieving optimum recovery of metal from mine waste rocks and assessing options to reduce the environmental impacts of the contained metals. A few studies [6] [10] [11] [12] [13] have been carried out to assess the potential for mineral/metal recovery from waste, but the size fractions as a major influencing factor are yet to be fully understood. What is known about rock size fractions analysis is largely based on information usually presented by mining and processing plant experts. Very limited empirical knowledge is known about the potential for metal recovery from mine waste using fractions size analysis.

On this backdrop, the central purpose of this project was to use MEGPA on various size fractions to investigate the potential for ore recovery from waste rock that is being produced at Boliden's Kevitsa open-pit mine. Also, the potential environmental benefits of reducing metalliferous drainage risk resulting from ore recovery were looked at.

The Kevitsa Ni-Cu-PGE deposit is located in the north of Finland in Lapland within the Sodankyla Municipality, $140 \mathrm{~km}$ north of the Arctic Circle. It is a large mine that has one of the largest nickel reserves in Finland. Kevitsa is positioned about $125 \mathrm{~km}$ east of the Finland/Sweden border. Access to the Kevitsa mine site is through well-maintained, sealed roads. Port facilities are accessible at Kemi Harbour which is approximately $290 \mathrm{~km}$ from the property by road [14].

The deposit is one of many Nickel sulphide deposits within the country, discovered in 1987. The Kevitsa deposit is hosted within a composite olivine-pyroxenite/ websterite complex, an ultramafic cumulate. Due to regional deformation and original magmatic emplacement, the Kevitsa deposit has increasing geometric complexities [15].

\section{Materials and Methods}

In addition to Multi-Elemental, Geochemical and Petrographic Analysis (MEGPA) of various size fractions, statistical techniques using specialized applications such as ZEISS mineralogical mining software packages have been applied extensively 
to examine economic metals concentration, distribution and recovery from the selected waste rock samples. The techniques incorporated in this methodology were not limited to; Sample collection from the Kevitsa mine, sample preparation, crushing, sieving and milling chemical analysis at accredited labs and interpretation. The research design (Figure 1) shows a systematic flow of the processes involved.

To have true fractions representation of $\mathrm{Ni}, \mathrm{Cu}$ and $\mathrm{S}$ from the bulk waste rock, 29 samples were carefully chosen from 114 bulk samples that had previously undergone geochemical analysis. The samples were initially screened into two major size fractions; $+22 \mathrm{~mm}$ and $-22 \mathrm{~mm}$ fractions. A few samples from

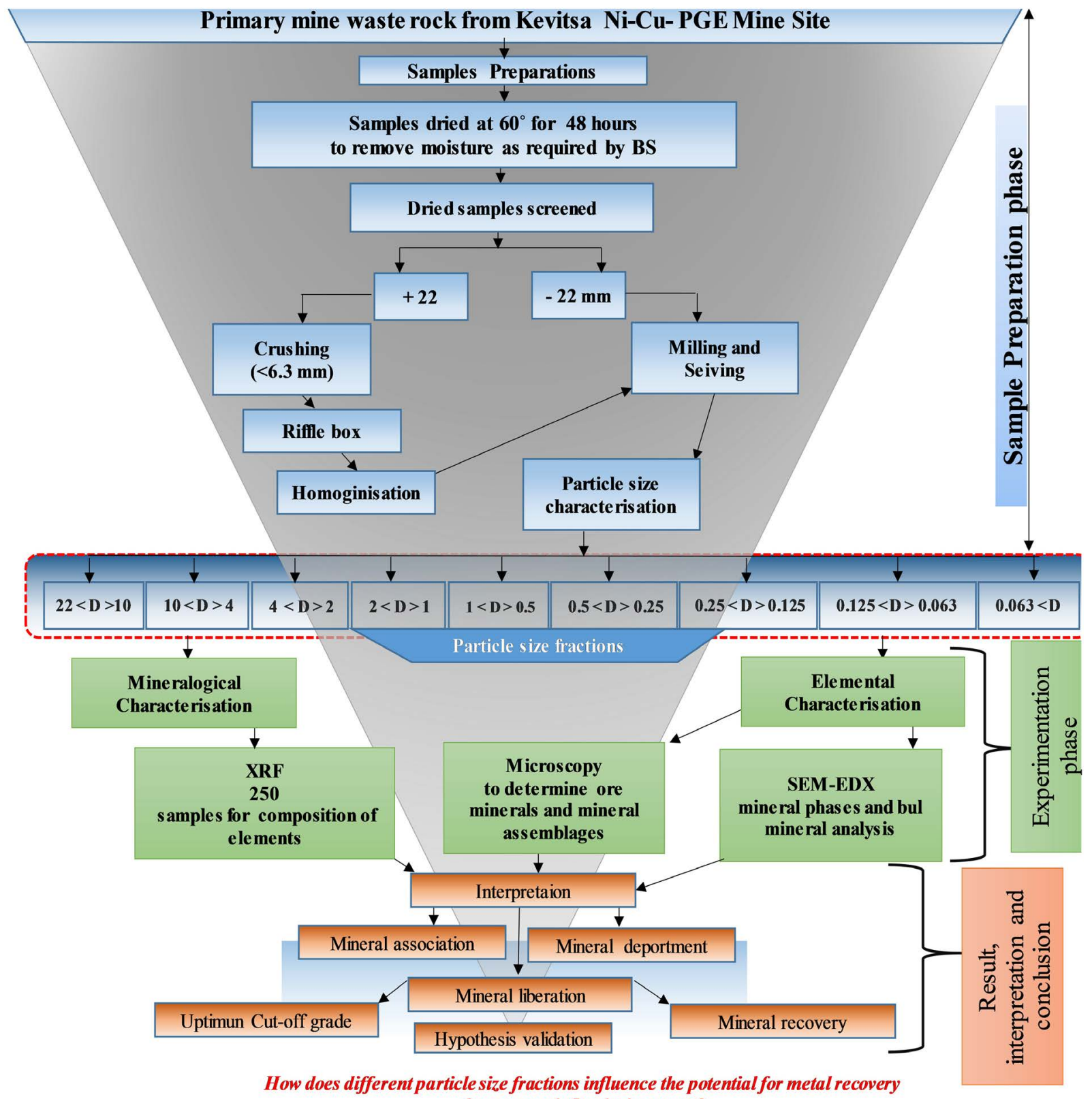
from a predefined mine waste?

Figure 1. Project research design flowchart. 
the $+22 \mathrm{~mm}$ size fractions were grabbed for petrographic and microscopic analysis.

The remaining bulk samples were subjected to comminution using a jaw crusher. The resultant product was homogenized and then milled into at least 9 major size fractions for subsequent MEGPA. Sieving was done to classify the milled particles into different size fractions to determine the percentage weight passing for each fraction.

\section{Results and Discussion}

\subsection{Particle Size Distribution and Mineralogical Characterization}

Particle size distribution (PSD) constitutes a part of the techniques used in fraction sizes analyses [16] for financial optimization of mining operations, especially after blasting has taken place. Profiles for the PSD of the waste rocks at Kevitsa mine show strong similarities irrespective of their contained metals (Figure 2). Mineralogical characterization of the waste sample categories shows a strong positive correlation concerning the three main mineral phases abundance for the selected samples (Figure 3). Furthermore; Tremolite, Clinopyroxene and the Mica Group of minerals were the mineral phases of abundance showing the host rock of the economic minerals to be igneous in origin.

\subsection{Microphotographic and Mineral Phases Analysis}

The principal mineral phases hosting the economic metals $(\mathrm{Cu}$ and $\mathrm{Ni})$ were identified to be pentlandite, pyrrhotite and chalcopyrite. These three minerals uncommonly occur in a close assemblage. However, comparatively, pyrrhotite appears as the dominant ore mineral and can be in association with any of the other mineral phases (Figure 4). The pentlandite and chalcopyrite occur as subhedral polycrystalline aggregates, commonly associated with pyrrhotite which appears as euhedral grains.

Generally, pentlandite within the samples analyzed shows parting cracks rather than normal cleavage, and may sometimes show evidence of alterations to millerite, Figure 5, Figure 6(a) \& Figure 6(b). Occasionally, the pentlandite

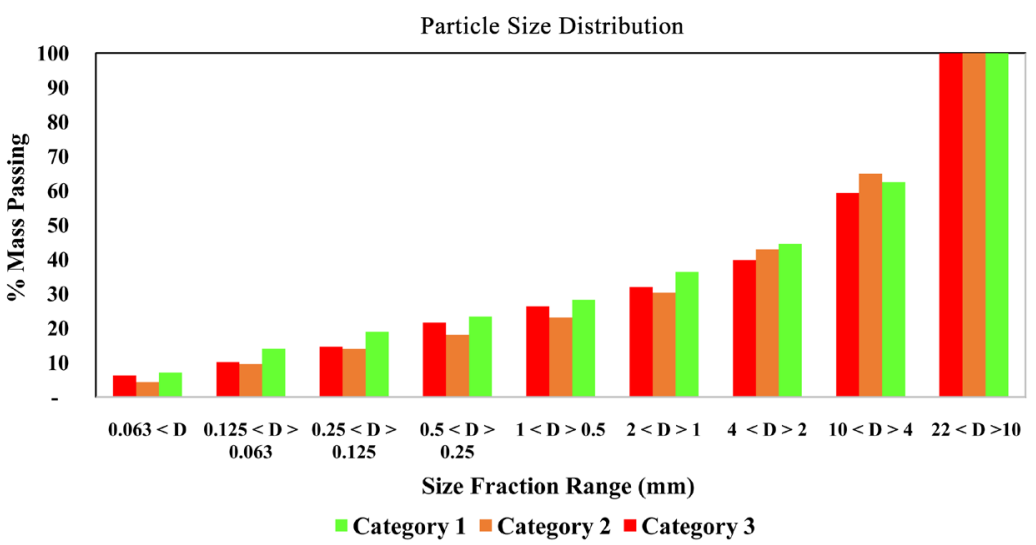

Figure 2. Particle sizes distribution profile. 


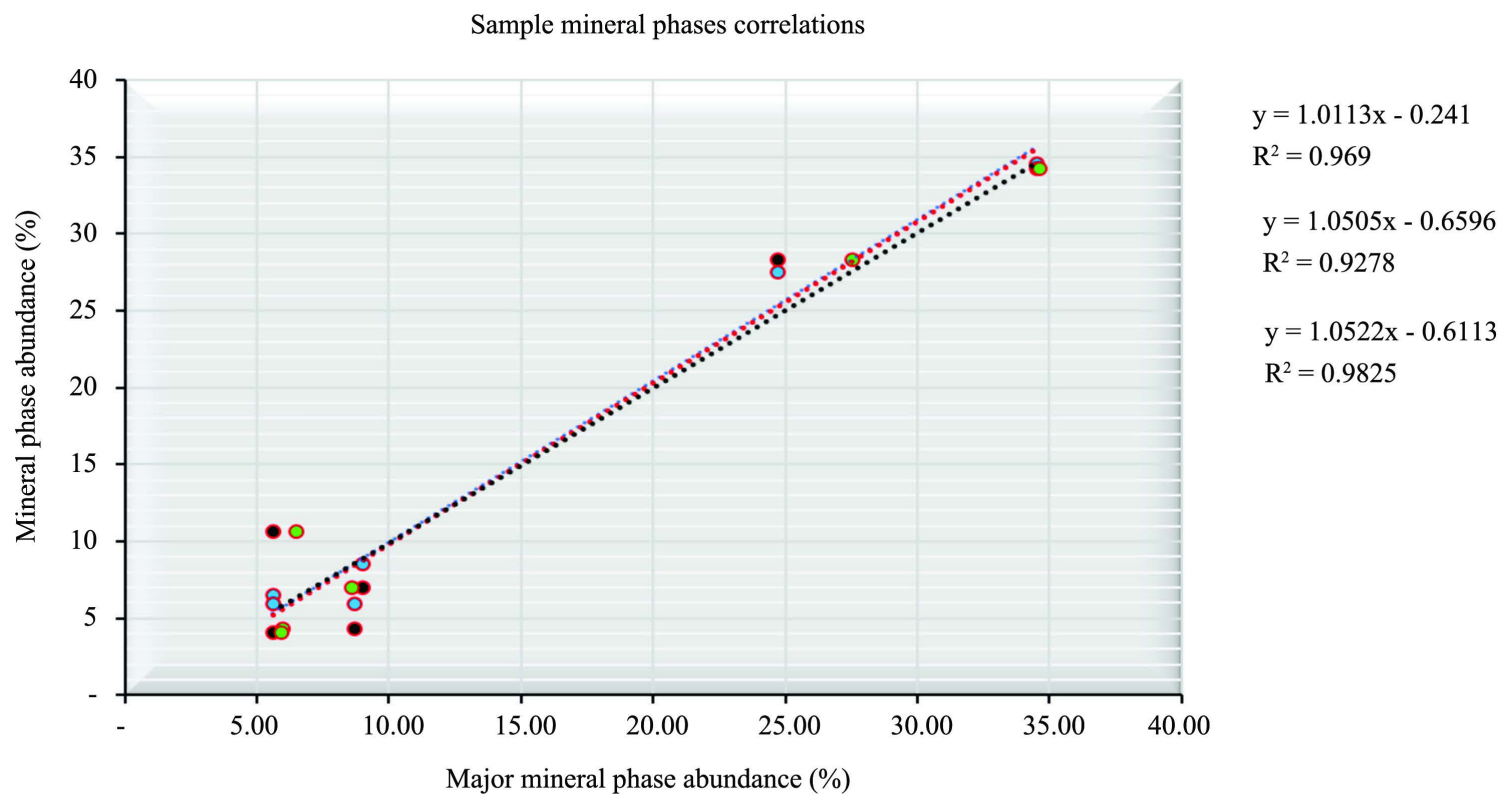

○ GCL0046-032 \& GCL0046-046

○ GCL0046-046 \& GCL0046-111

…... Linear (GCL0046-032 \& GCL0046-111)
- GCL0046-032 \& GCL0046-111

Linear (GCL0046-032 \& GCL0046-046)

…... Linear (GCL0046-046 \& GCL0046-111)

Figure 3. Waste samples major minerals phase abundance correlation.

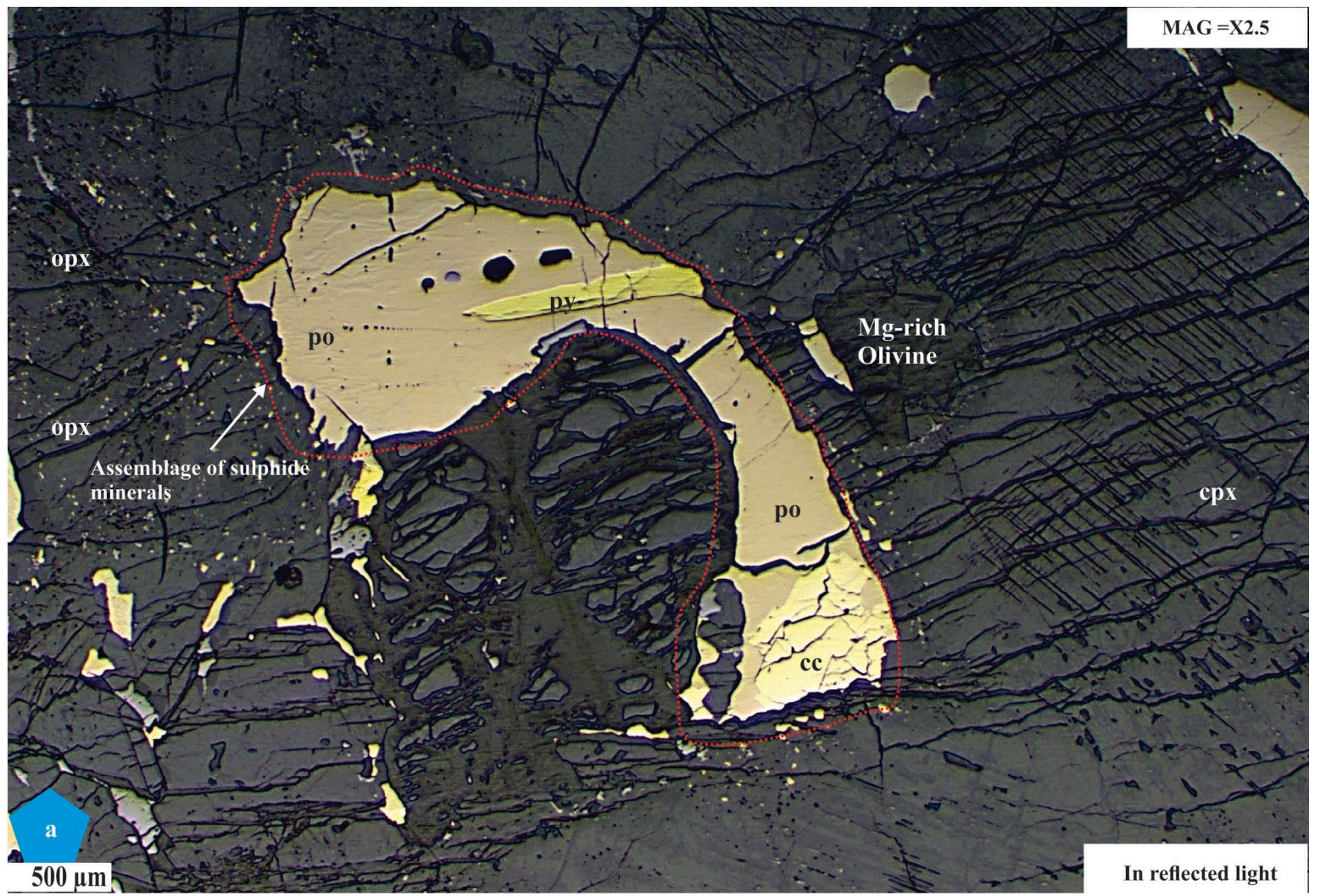

Figure 4. Major sulphide minerals assemblage $(\mathrm{py}=$ Pyrite, $\mathrm{cc}=$ chalcopyrite, po $=$ pyrrhotite, $\mathrm{cpx}=$ clinopyroxene, opx $=$ orthopyroxene). 


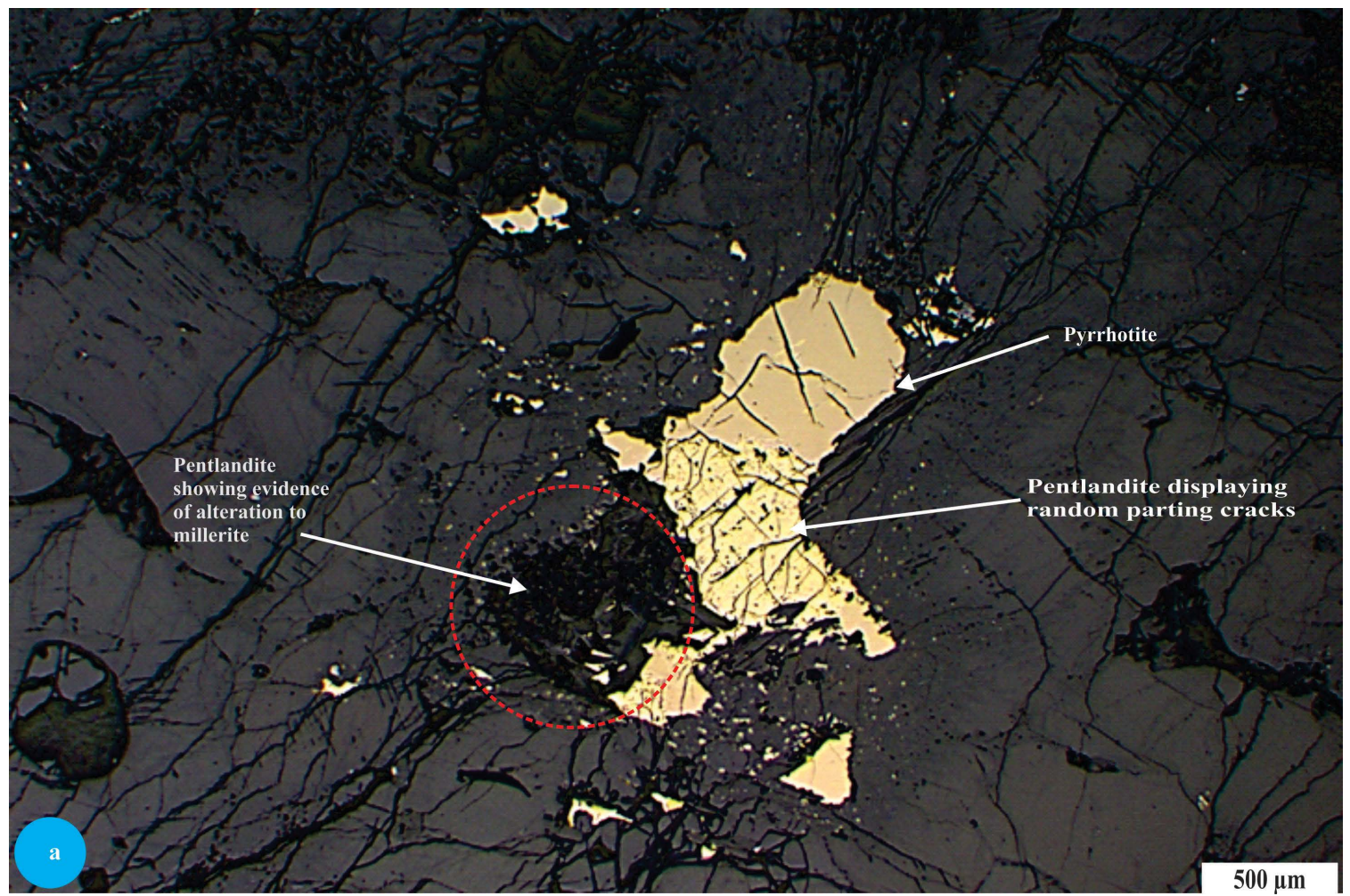

Figure 5. Pentlandite, the principle Ni-sulphide hosting mineral coexisting with pyrrhotite showing parting cracks and evidence of alteration to millerite.

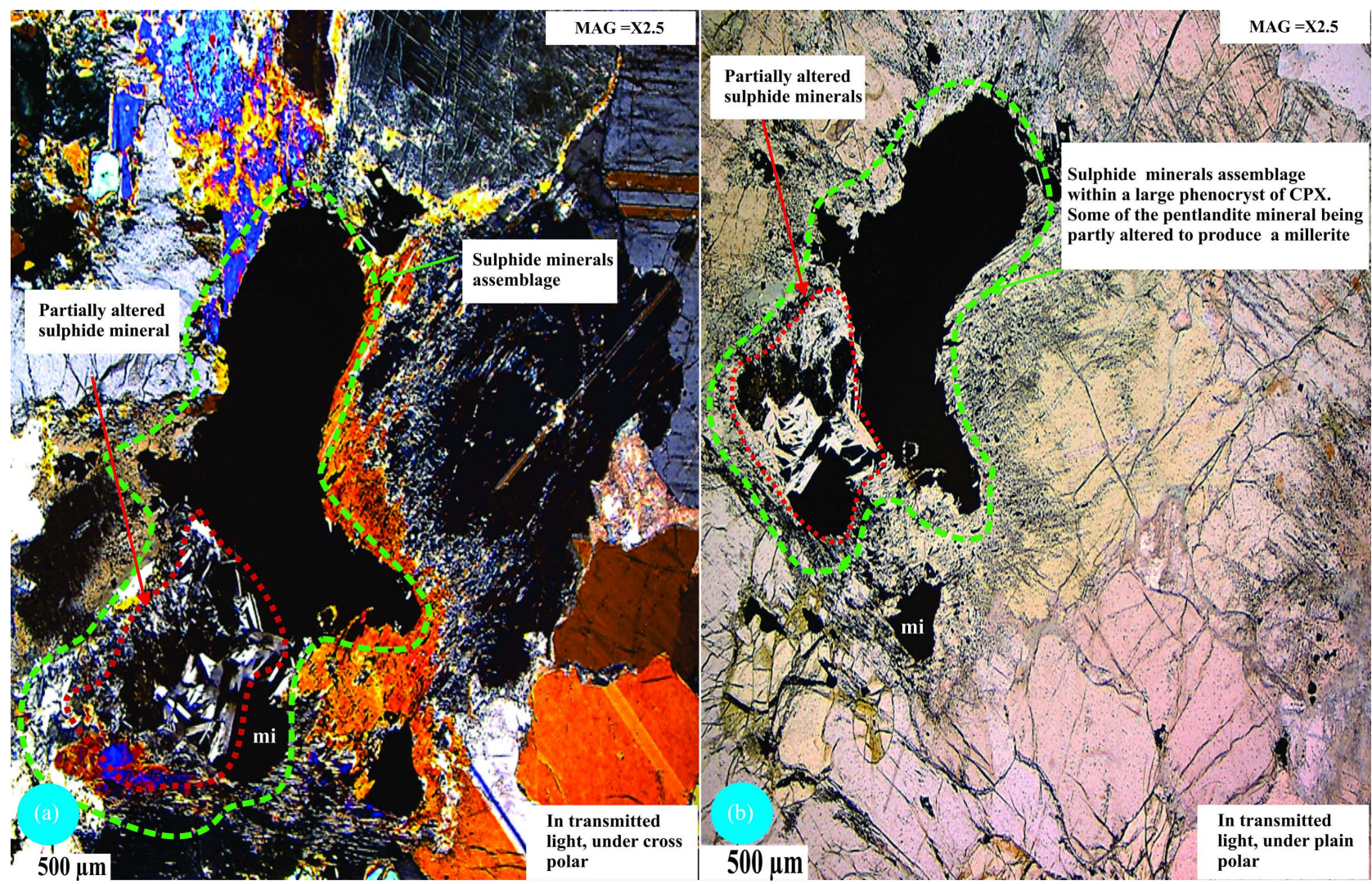

Figure 6. Partially altered sulphide mineral assemblages' association within the major silicate minerals (Olivine \& pyroxenes). 
appears as small to medium exsolution flames within the pyrrhotite. The prevailing silicate mineral in close association with the sulphides is olivine (Mg-rich end member-fosterite) and pyroxene (clinopyroxene and orthopyroxene). Clinopyroxene forms an oikocryst having the inclusion of tremolite which bears the fine sulphides that are completely locked with the grains.

In order to further simplify questions about the automated mineralogy with special attention to carbonate and sulphide textures, and their liberation, four size fractions were analyzed. A Digital photomicrograph was taken using a high-resolution digital camera to have a pictorial estimate of relative phase abundance. It was observed that the main minerals across the sample are very alike, and are gabbroic in origin. Result from the automated mineralogy revealed that tremolite is the predominant mineral phase. Liberation across the size fractions increase from coarse to fine grains. This is in line with what Guldris, L. et al., (2020) [17] ascertained about the liberation of ore minerals, as a function of rock fraction size and texture.

\subsection{Mineralogical Characterization Using X-Ray Fluorescence (XRF), X-Ray Diffraction (XRD) and Scanning Electron Microscope Energy Disperse X-Ray (SEM-EDX)}

\subsubsection{Application of X-Ray Fluorescence (XRF)}

A Mini-pal XRF was used, which is a compact energy dispersive $\mathrm{x}$-ray spectrometer intended for the elemental analysis of a varied range of samples. This system is managed by a PC running the assigned mini analytical software for the detection and measurement of the element in a sample (solid, powder and liquid) usually from Sodium (Na) to Uranium (U). The pulverized sample is loaded into the sample chamber of the spectrometer and a current is applied to produce the $\mathrm{x}$-rays that stimulate the sample and the spectrum from the sample is now analyzed to determine the concentration of the element in each sample.

\subsubsection{Application of X-Ray Diffraction (XRD)}

An XRD analysis was carried out using a Philips PW1710 Automated Powder Diffractometer, which used a Copper $(\mathrm{CuK} \alpha)$ Radiation power source at $35 \mathrm{kV}$ $40 \mathrm{~mA}$. The XRD was operated using PW1877 analytical power diffraction (APD) version 3.6 software while phase identification was carried out using PW1876 PC-Identify version $1.0 \mathrm{~b}$ software. The sample fraction used was $<2.3$ $\mathrm{mm}$ which was pulverized and riffle box split for homogeneity. The powdered fraction from each sample was packed into an aluminium holder which was then placed in the sample holder of the Goniometer and bombarded with X-Rays generated from the Copper X-ray source. The diffracted rays are collected by a detector and the information is relayed to the computer. Using the Bragg equation $(\mathrm{n} \lambda=2 \mathrm{~d} \sin \theta)$, the diffracted rays are converted to d-values of specific intensities. This information (the result) was then shown graphically in the form of a diffraction pattern (Diffractogram). The diffractogram from the sample was then matched against the detector database using the PW1876 PC-Identify version 1.0 b software. 


\subsubsection{Application of Scanning Electron Microscope Energy Disperse X-Ray (SEM-EDX)}

Quantitative automated mineralogical analysis was undertaken to characterize the bulk mineral deportment of the Kevitsa waste rock material. Three representative waste rock samples of varying known geochemical composition were used to create a polished block which was then carbon-coated to $10 \mathrm{~nm}$. The polished blocks from each sample were then analyzed using a ZEISS EVO MA 25 scanning electron microscope (SEM) which was fitted with a Bruker flash $\mathrm{x}$-ray detector for energy-dispersive X-ray spectroscopy (EDX). A phase mineral characterization scheme was developed for the waste rock samples using ZEISS Mineralogic Mining software which controlled both the SEM and the EDX instruments. Reporting of the sample mineralogy took the form of the weighted percentage of each mineral.

Using these equipment revealed that tremolite is the predominant mineral phase across all the samples (Figure 7). However, except for a few samples, magnesioferrite grading toward magnetite has been identified as a very minor but significant component of the iron-rich portion of the waste sample. To understand the influence of particle size in terms of metal concentration in the waste rocks and their subsequent metal recovery bulk samples were divided into three priority categories (Low $\mathrm{Ni}$, Medium $\mathrm{Ni}$ and High $\mathrm{Ni}$ all in ppm). It follows from the results that 15 elements were reported $(\mathrm{K}, \mathrm{Fe}, \mathrm{S}, \mathrm{Si}, \mathrm{Ti}, \mathrm{Ba}, \mathrm{Co}, \mathrm{Cr}$, $\mathrm{Cu}, \mathrm{Mn}, \mathrm{Ni}, \mathrm{Pb}, \mathrm{Sr}, \mathrm{V}$ and $\mathrm{Zn})$. Of which, three $(\mathrm{Ni}, \mathrm{Cu}$ and $\mathrm{S})$ are critically important for both metal recovery and (AMD) potential.

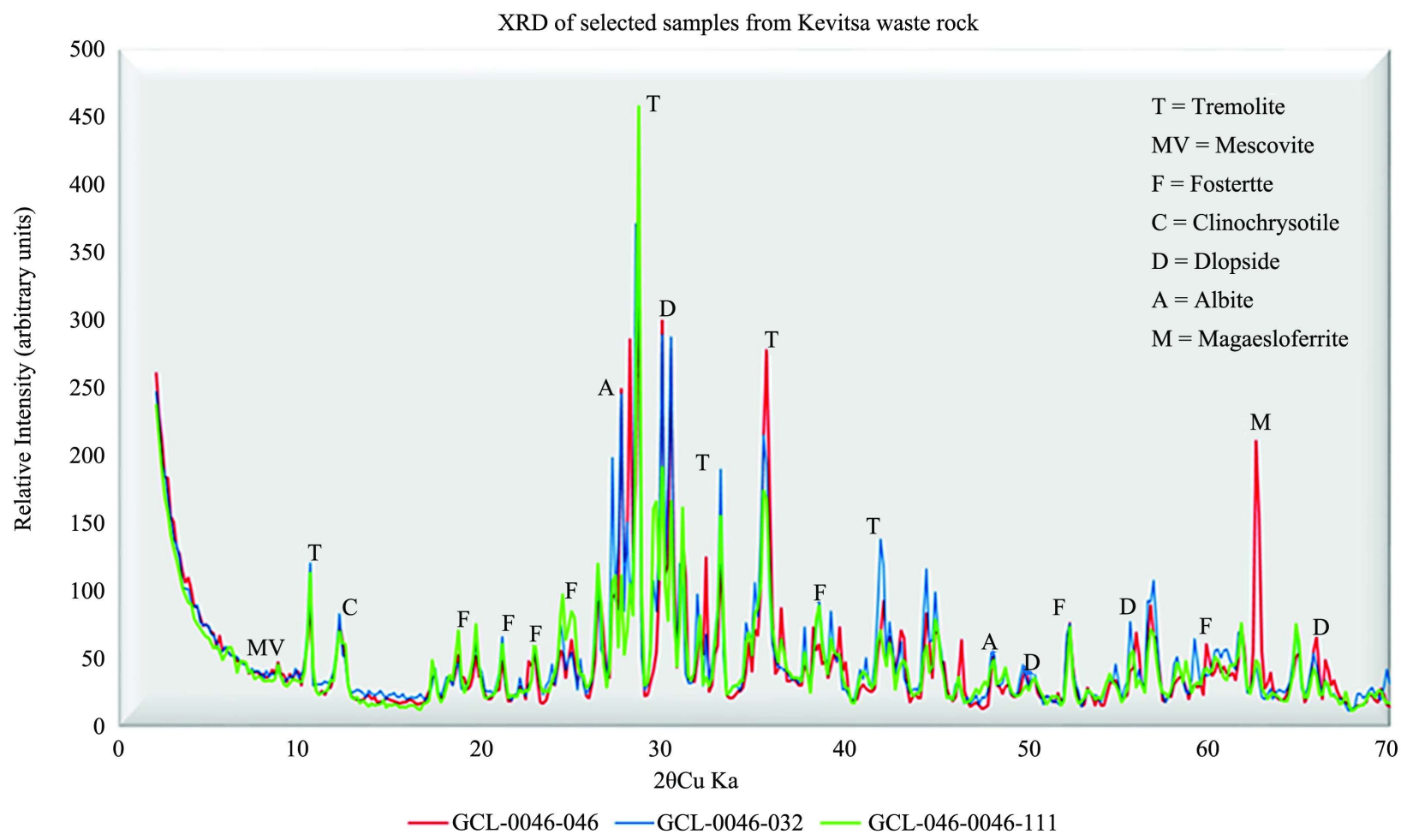

Figure 7. X-ray diffraction diffractogram of copper nanoparticles for three samples from Kevitas waste rock. 
Sulphur appears erratic within size fractions $1 \mathrm{~mm}-0.25 \mathrm{~mm}$, especially for the medium and High Ni values due to the influence of till samples within the waste rocks. When the sulphur values of the till samples have been filtered out of the average composite merged samples, the trend of the sulphur contents across the various size fractions become obvious and consistent with a decrease in the size fractions. The maximum $\mathrm{Ni}$ and $\mathrm{Cu}$ values correspond to the smallest size fraction $(0.063 \mathrm{~mm})$ for each of the three priority sample categories. The result further indicates that the sulphur contents increase with a decrease in the fraction sizes, but increase with a corresponding increase in the Ni content in the three samples (Figure 8 and Figure 9).

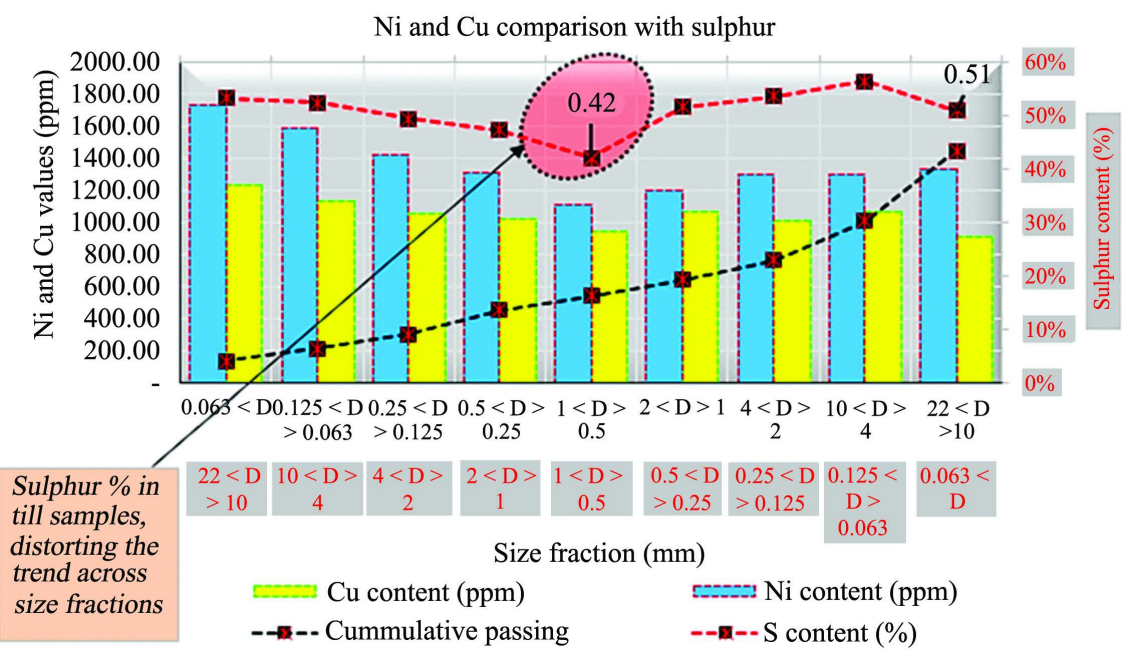

Figure 8. $\mathrm{Ni}$ and $\mathrm{Cu}$ values (ppm) comparison with $\mathrm{S}$ contents (\%) across various size fractions for the waste samples, showing the influence of sulphur contents in the till samples (Sagging the trend across the samples).

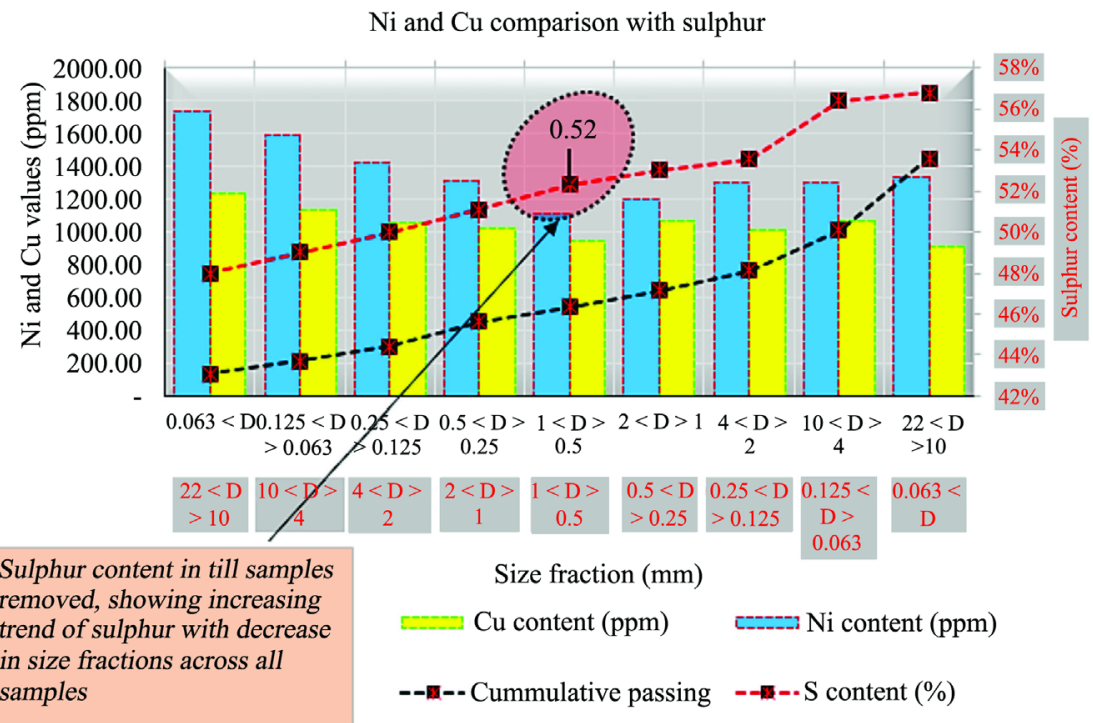

Figure 9. $\mathrm{Ni}$ and $\mathrm{Cu}$ values comparison with $\mathrm{S}$ contents (\%) across various size fractions for the waste samples, when the sulphur contents in the till samples have been filtered out (No sagging in the trend across the samples). 


\subsection{Metal Recovery Predictive Model and Deportment of Ni and $\mathrm{Cu}$}

Figure 10 with the embedded table represents a predictive model for $\mathrm{Ni}, \mathrm{Cu}$ and $S$ distribution in the Kevitsa waste rock. The model is broadly divided into two zones; the "above cut-off" and "below cut-off" zones. The model shows that reducing the size fractions will increase the metal recovery potential of the low-grade waste by at least $11 \%$, and reduce metalliferous AMD risk to over $13 \%$. Accounting for stoichiometric controls of $\mathrm{Ni}$ and $\mathrm{Cu}$ for the three representative samples, $100 \%$ of $\mathrm{Cu}$ is hosted within chalcopyrite and $100 \%$ of $\mathrm{Ni}$ hosted in pentlandite for each sample and all size fractions.

\subsection{Mode of Liberation}

All the samples show a marked increase in carbonate liberation moving from the coarsest size fractions to the finest size fractions. Comparatively; carbonate liberation in all samples, and almost every size fraction shows a higher degree of liberation than in $\mathrm{Cu}$ and $\mathrm{Ni}$ sulphides. For $\mathrm{Cu}$ and $\mathrm{Ni}$ sulphides (Figure 11),

\begin{tabular}{|c|c|c|c|c|c|}
\hline $\begin{array}{c}\text { Max average } \\
\mathrm{Ni}(\mathrm{ppm})\end{array}$ & $\begin{array}{c}\text { Min average } \\
\mathrm{Ni}(\mathrm{ppm})\end{array}$ & $\begin{array}{c}\text { Max average } \\
\mathrm{Cu}(\mathrm{ppm})\end{array}$ & $\begin{array}{c}\text { Min average } \\
\mathrm{Cu}(\mathrm{ppm})\end{array}$ & $\begin{array}{c}\text { Max average } \\
\mathrm{S}(\%)\end{array}$ & $\begin{array}{c}\text { Min average } \\
\mathrm{S}(\%)\end{array}$ \\
\hline 1418.52 & 884.83 & 1032.94 & 646.51 & 0.47 & 0.34 \\
\hline $15 \%$ & $9 \%$ & $14 \%$ & $9 \%$ & $13 \%$ & $9 \%$ \\
\hline
\end{tabular}

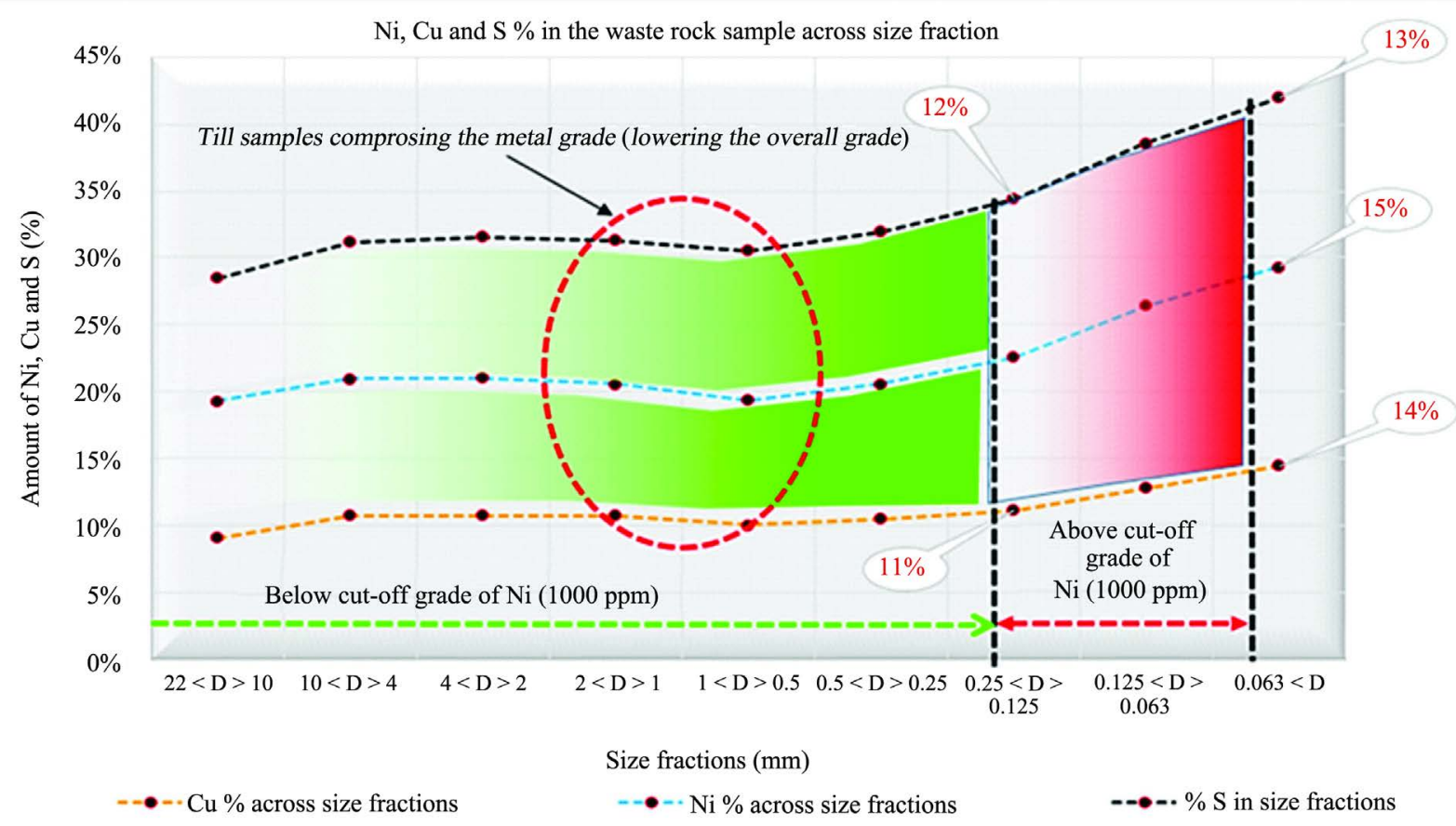

Figure 10. Metal model grades distribution (\%) and S content (\%) in the samples waste rock across size fractions with a cut-off grade. 


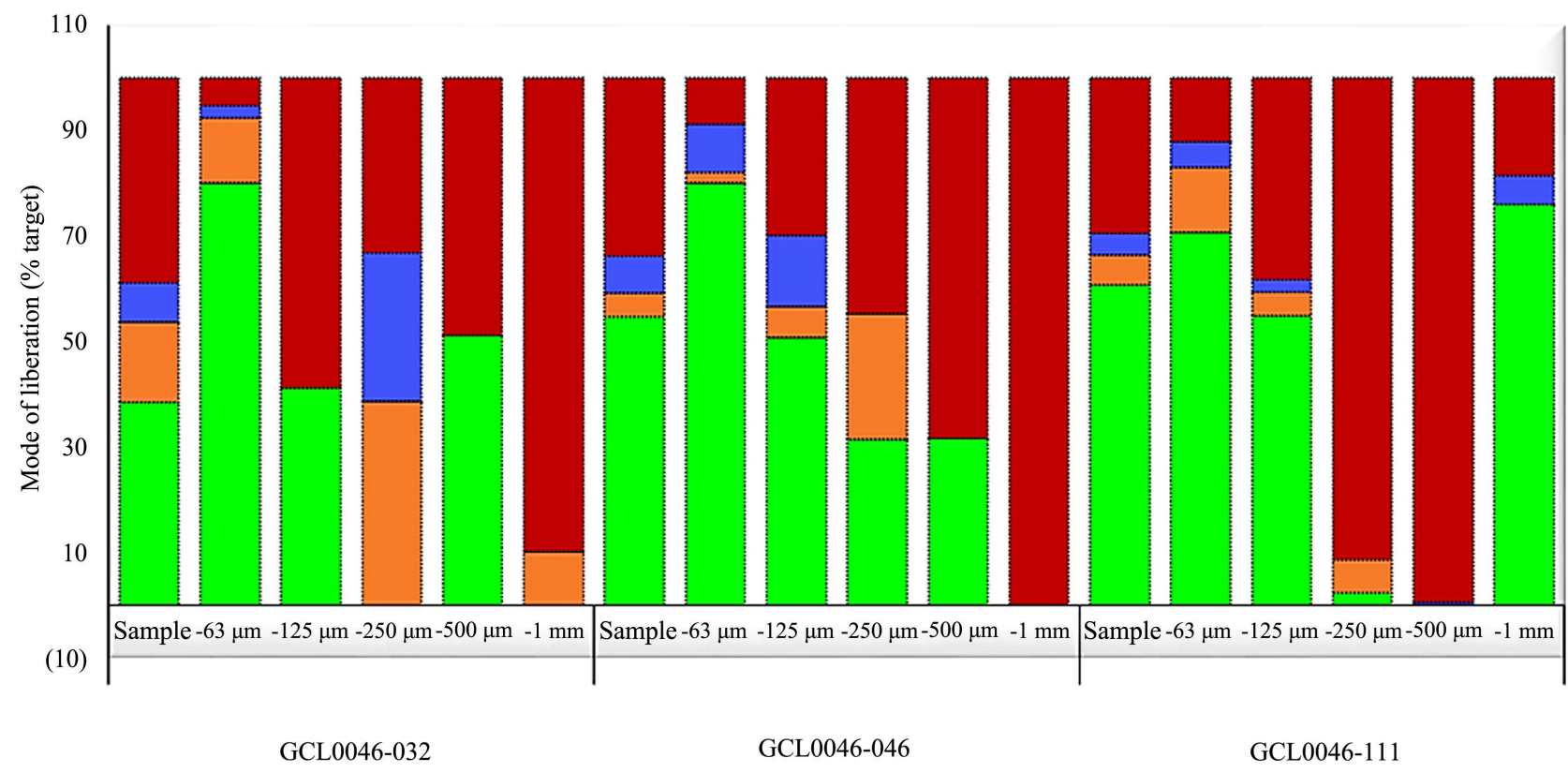

Sample and Size fractions

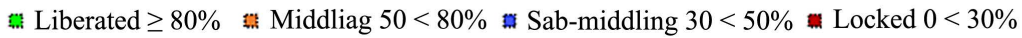

Figure 11. Ni and $\mathrm{Cu}$-sulphides mode of liberation for from the waste rock samples across size fractions.

liberation is moderate to good for all three samples, and again only slightly higher in sample GCL-0046-111 but strikingly lower in sample GCL-0046-032. Liberation levels for all samples analyzed are $\sim 40 \%-60 \%$, being increasing to $60 \%-70 \%$ if middlings is also considered. Moreover, all three samples show a consistent proportion of $30 \%-40 \%$ of the $\mathrm{Cu}$ and $\mathrm{Ni}$ sulphides that can be regarded locked. When considered across the size fractions there is an increase in $\mathrm{Cu}$ and $\mathrm{Ni}$ sulphide liberation when moving from the coarsest size fractions to the finest size fractions.

\subsection{Grade Optimization for $\mathrm{Ni}$}

Optimization of grade using Net Smelter Return calculation for the potential of $\mathrm{Ni}$ recovery from the waste rock showed that the NSR values vary across the three particle size limits, with $<4 \mathrm{~mm}$ size fraction having the highest NSR values for each of the Ni grade categories. The $>22 \mathrm{~mm}$ fraction has the least NSR values. For optimum Ni recovery from the existing mined-out waste rocks, $<1.5$ $\mathrm{mm}$ is a suitable cut-off based on size fractions, as it above the defined NSR value of $15 \%$ that corresponds to $\geq 1000 \mathrm{ppm}$ of $\mathrm{Ni}$ concentration saleable product (Figure 12). 


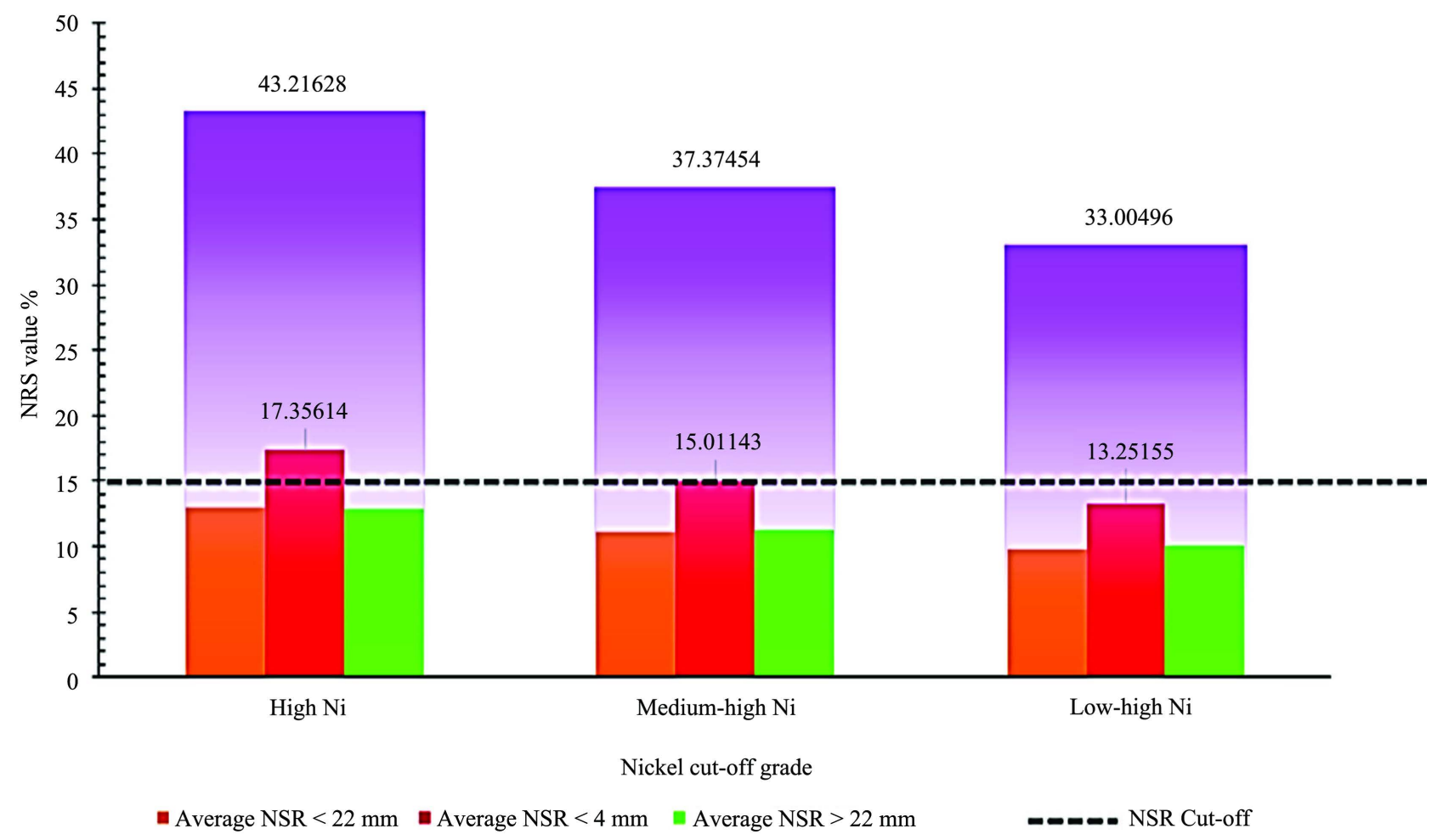

Figure 12. Average NSR and Ni cut-off grade for Kevitsa waste rock assessment.

\section{Conclusions}

An investigation of optimizing the potential for metal recovery from mine waste rock had been completed. The primary aim of the project was to determine if metal could be recovered from mine waste rocks using MEGPA. This study improves the understanding of what size fractions are optimal for metal recovery from magmatic Ni-Cu-PGE waste rock and established an environmental risk that can be controlled and/or mitigated by removing fines from waste (metalliferous drainage risk management benefit).

An initial hypothesis was that the recovery of metals from mining-related waste would be significantly increased with decreasing particle size. It was found that there is potential for $\sim 65 \%$ of nickel and $\sim 60 \%$ copper to be recovered in the finer particle fractions compared to $\sim 38 \%$ nickel and $\sim 25 \%$ copper in the coarsest fractions. Therefore, it can be concluded that various size fractions have a significant influence on the amount of metal recovery from mine waste.

From the particle size distribution curves that were constructed, the profiles revealed similarities across low, medium and high waste categories, though this method is susceptible to human error during sample preparation.

It can therefore be summarised that:

1) Kevitsa waste rock has a high recovery rate that can be achieved at $1.5 \mathrm{~mm}$ fractions size, with optimum recovery at $\leq 1 \mathrm{~mm}$. For all target minerals, there is a rough cut-off between 53 - $106 \mu \mathrm{m}$ below which the liberation is noticeably 
improved, and that Cut-off for the sulphides is usually quite sharp;

2) Nickel sulphides are concentrated in the fines, and they are more liberated in the fines. The "Econo-environmental" implication of Ni sulphides in the fines is key to two of the three pillars of sustainability (Environmental and Socio-economic). As these fines are optimal for both reducing nickel release potential and metal recovery;

3) Nickel in the coarser fractions is less liberated and have lower concentration, as such lower release potential for environmental degradation and resource recovery;

4) There is substantial potential to reduce the impacted seepage of nickel mobilization into the environment from the waste dump;

5) The main sulphides are pyrrhotite, pentlandite and chalcopyrite with occasional pyrite. The main carbonates are calcite and to lesser extent dolomite, with trace ankerite.

\section{Acknowledgements}

This project would have somewhat been unmanageable without the help of my academic supervisor, Dr. Peter Brabham (Cardiff University, UK), and my astute project placement supervisor Steve Pearse-the Chief geoscientist at Mining and Environmental Management (MEM) that provided the financial resources to execute the project. My thanks go to Dr. Timothy Jones who has always been there to support me in challenging moments since joining the School of Earth and Ocean Sciences, Cardiff University, UK. Also, my profound gratitude to Geochemic Ltd. that provided logistical support for the project. A distinct reference to Dr. Andrew Barnes, the managing director of Geochmic Ltd. that provided me with the opportunity to carry out this project at the lab with consistent support throughout. By the same token, I would like to thank Dr. Mark Robert and Mr. Rhys Salvage for their supervision at the lab. A very big thanks to Cardiff University in the UK for capacitating me with technical skills that are second to none.

Finally, my infinite thanks to Dr. Sahr Fillie of Geology Department, Fourah Bay College, University of Sierra Leone, Dr. Gbanie and Dr. Momoh all two of the Geography Department Fourah bay College, University of Sierra Leone. They had, and have always been mentors to me and shoulders to lean on in challenging times.

\section{Conflicts of Interest}

The author declares no conflicts of interest regarding the publication of this paper.

\section{References}

[1] Cho, S.H., Nishi, M., Yamamoto, M. and Kaneko, K. (2003) Fragment Size Distribution in Blasting. Materials Transactions, 44, 951-956. https://doi.org/10.2320/matertrans.44.951

[2] Coello-Velázquez, A.L., Quijano Arteaga, V., Menéndez-Aguado, J.M., Pole, F.M. 
and Llorente, L. (2019) Use of the Swebrec Function to Model Particle Size Distribution in an Industrial-Scale Ni-Co Ore Grinding Circuit. Metals, 9, 882. https://doi.org/10.3390/met9080882

[3] Sousa, R., Futuro, A., Pires, C.S. and Leite, M.M. (2017) Froth Flotation of Aljustrel Sulphide Complex Ore. Physicochemical Problems of Mineral Processing, 53, 758-769. https://doi.org/10.5277/PPMP170207

[4] Appannagari, D.R.R. (2017) Environmental Pollution Causes and Consequences: A Study. North Asian International Research Journal of Social Science and Humanities, 3, 151-161.

[5] Tyagi, S., Garg, N. and Paudel, R. (2014) Environmental Degradation: Causes and Consequences. European Researcher, 81, 1491-1498.

https://doi.org/10.13187/er.2014.81.1491

[6] Mankosa, M.J., Kohmuench, J.N., Christodoulou, L. and Luttrell, G.H. (2016) Recovery of Values from a Porphyry Copper Tailings Stream.

[7] Markovic, Z.S., Jankovic, A. and Tomanec, R. (2008) Effect of Particle Size and Liberation on Flotation of a Low-Grade Porphyry Copper Ore. Journal of Mining and Metallurgy A: Mining, 44, 24-30.

[8] Siddiqui, F., Shah, S. and Behan, M. (2009) Measurement of Size Distribution of Blasted Rock Using Digital Image Processing. Journal of King Abdulaziz University-Engineering Sciences, 20, 81-93.

[9] Jug, J., Strelec, S., Gazdek, M. and Kavur, B. (2017) Fragment Size Distribution of Blasted Rock Mass. IOP Conference Series. Earth and Environmental Science, 95, Article ID: 042013. https://doi.org/10.1088/1755-1315/95/4/042013

[10] Nagaraj, D.R. (2005) Minerals Recovery and Processing. In: Kirk-Othmer Encyclopedia of Chemical Technology, John Wiley \& Sons, Inc., Hoboken, 2-10. https://doi.org/10.1002/0471238961.1309140514010701.a01.pub2

[11] Bellenfant, G., Guezennec, A.G., Bodenan, F., D’Hugues, P. and Cassard, D. (2013) Reprocessing of Mining Waste: Combining Environmental Management and Metal Recovery? Proceedings of the Eighth International Seminar on Mine Closure, Australian Centre for Geomechanics, Cornwall, September 2013, 571-582. https://doi.org/10.36487/ACG_rep/1352_48_Bellenfant

[12] He, J. and Kappler, A. (2017) Recovery of Precious Metals from Waste Streams. Microbial Biotechnology, 10, 1194-1198. https://doi.org/10.1111/1751-7915.12759

[13] Wang, M., Tan, Q., Chiang, J.F. and Li, J. (2017) Recovery of Rare and Precious Metals from Urban Mines-A Review. Frontiers of Environmental Science \& Engineering, 11, Article No. 1. https://doi.org/10.1007/s11783-017-0963-1

[14] Gregory, J., Journet, N., White, G. and Lappalainen, M. (2011) NI 43-101 Technical Report for the Mineral Resources of the Kevitsa Project.

[15] Maier, W., Lahtinen, R. and O’Brien, H. (2015) Mineral Deposits of Finland. 2nd Edition, Elsevier Ltd., Amsterdam, 155-160.

[16] Mohamed, F., Riadh, B., Abderazzak, S., Radouane, N., Mohamed, S. and Ibsa, T. (2019) Distribution Analysis of Rock Fragments Size Based on the Digital Image Processing and the Kuz-Ram Model Cas of Jebel Medjounes Quarry. Aspects in Mining \& Mineral Science, 2, 325-329. https://doi.org/10.31031/AMMS.2019.02.000545

[17] Guldris Leon, L., Hogmalm, K.J. and Bengtsson, M. (2020) Understanding Mineral Liberation during Crushing Using Grade-by-Size Analysis-A Case Study of the Penuota Sn-Ta Mineralization, Spain. Minerals, 10, 164. https://doi.org/10.3390/min10020164 